\title{
In Memory of Professor Alan L Kistler
}

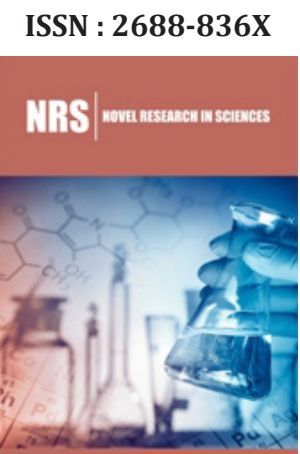

*Corresponding author: Siavash $\mathrm{H}$ Sohrab, Robert McCormick School of Engineering and Applied Science, Department of Mechanical Engineering, Northwestern University, USA

Submission: 望-1 July 09, 2019

Published: 留July 11, 2019

Volume 1 - Issue 3

How to cite this article: Siavash H Sohrab. In Memory of Professor Alan L Kistler. Nov Res Sci.1(3). NRS.000513.2019.

DOI: 10.31031/NRS.2019.1.000513

Copyright@ Siavash H Sohrab, This article is distributed under the terms of the Creative Commons Attribution 4.0 International License, which permits unrestricted use and redistribution provided that the original author and source are credited.

\section{Siavash H Sohrab*}

Robert McCormick School of Engineering and Applied Science, Department of Mechanical Engineering, Northwestern University, USA

\section{Opinion}

As a friend and colleague of Alan from Department of Mechanical Engineering at Northwestern University and on behalf of our department and its chair Prof. Kevin Lynch, I express my condolences to Alan's family and his friends.

As many of you know, Alan was an expert in fluid mechanics and got his $\mathrm{PhD}$ in 1955 from Johns Hopkins University and after two years serving in U.S. Army he worked at Jet Propulsion Laboratory on turbulent fluid mechanics and from 1961-1965 he was a professor at Yale University. He then returned to California Institute of Technology's Jet Propulsion Laboratory as manager of Fluid Physics Division. In 1969, he joined the Department of Mechanical Engineering at Northwestern University.

Amongst many warm memories, I recall that once a week Alan and I along with Art Kovitz and Dick Tankin, who also worked in the area of fluid mechanics, we went to lunch at an all-you-can-eat Polish restaurant called Lone Tree. I am not going into details regarding the amounts of food Art Kovitz and Dick Tankin consumed!

During the renovation of Technological Institute, the university decided to throw away some old machinery against the wishes of both Alan and I. Finally, when they wanted to discard an old Pratt-Whitney jet engine, Alan and I we took the engine apart, and Alan took some of the turbine blades and I took one of the combustors.

Alan was an expert in turbulent flows and precision measurement in such flows. In my recent review of one of his papers [1], I noted some data on velocity profiles in turbulent supersonic flow over a flat plate obtained at Mach numbers $(1.72,3.56,4.67)$ as shown in Figure 1. Alan's data in Figure 1 appears to be in accordance with the recent velocity profile shown in Figure 2 based on prediction of a recent scale-invariant statistical theory of turbulence. The exact comparisons with two-part solution shown in Figure 2 require further future examination.

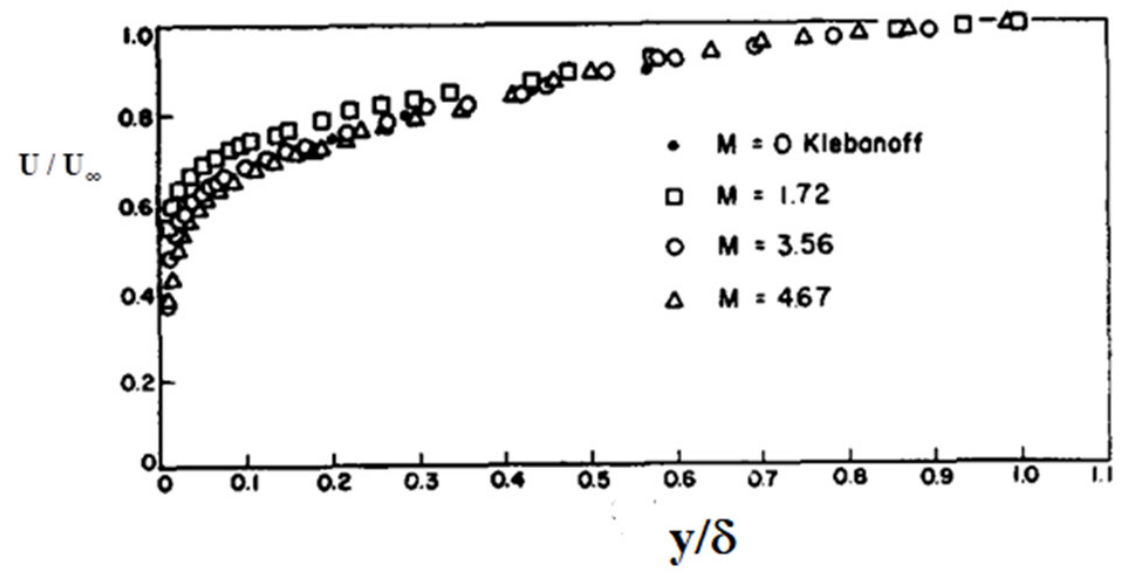

Figure 1: Mean-velocity profile. The Klebanoff data are from NACA Report. 1247 [1]. 


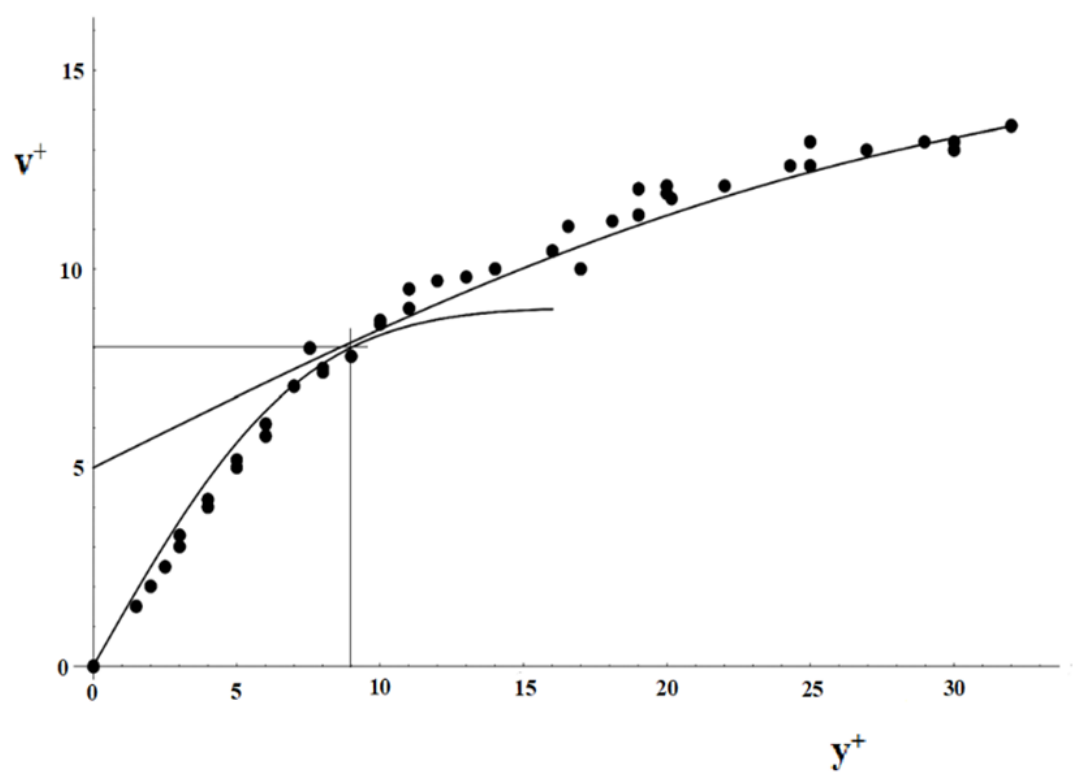

Figure 2: Comparisons of predicted velocity profile with experimental data from Ref. 46 of [3].

Another important contribution of Alan to turbulent fluid mechanics is the Corrsin-Kistler equation [2]

$$
\frac{\partial}{\partial x_{i}} \overline{\left(u_{i}^{\prime} u_{j}^{\prime}\right)}=\frac{1}{2} \frac{\partial}{\partial x_{i}} \overline{\left(u_{j}^{\prime} u_{j}^{\prime}\right)}
$$

To reveal connections between Corrsin-Kistler equation in statistical theory of turbulence and kinetic theory of gas in thermodynamics [3], one can write

$$
\overline{\left(u_{i+}^{\prime}-u_{j+}^{\prime}\right)^{2}}=\overline{\left(u_{i+}^{\prime}\right)^{2}}+\overline{\left(u_{j+}^{\prime}\right)^{2}}-2 \overline{\left(u_{i+}^{\prime} u_{j+}^{\prime}\right)}
$$

For homogeneous isotropic turbulence Boltzmann equipartition of energy assuming $\mathrm{m}=1$ gives

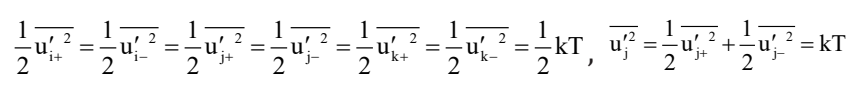

resulting in "atomic" internal energy $\hat{u}=\overline{u_{i}^{\prime 2}}+\overline{u_{j}^{\prime 2}}+\overline{u_{k}^{\prime 2}}=3 k T$. Hence, in the limit of "stationary" isotropic homogeneous turbulence $\overline{\left(u_{i+}^{\prime}-u_{j+}^{\prime}\right)^{2}} \rightarrow 0$ the results in Eqs. (2-3) lead to Corrsin-Kistler equation (1)

$$
\frac{\partial}{\partial \mathrm{x}_{\mathrm{i}}} \overline{\left(\mathrm{u}_{\mathrm{i}+}^{\prime} \mathrm{u}_{\mathrm{j}+}^{\prime}\right)}=\frac{1}{2} \frac{\partial}{\partial \mathrm{x}_{\mathrm{i}}} \overline{\left(\mathrm{u}_{\mathrm{j}}^{\prime} \mathrm{u}_{\mathrm{j}}^{\prime}\right)}=\frac{\partial \kappa}{\partial \mathrm{x}_{\mathrm{i}}}
$$

where $\kappa=\frac{1}{2} \overline{\left(\mathrm{u}_{\mathrm{j}}^{\prime} \mathrm{u}_{\mathrm{j}}^{\prime}\right)}$ is turbulent kinetic energy.

Interestingly, the important problem of turbulence is also related to the universal problem of the nature of physical space that was recently identified as a compressible tachyon fluid, Aristotle fifth element, or Casimir vacuum [3]. Plato believed that the world was initially created from the state of total chaos. Many scientists and philosophers, including Huygens, Euler, and Newton, associated the infinite space and time (extension and duration) with the body of the Almighty that is everywhere and everywhen and within which all creation resides, all made of the same cloth, and all connected as part of a continuum constituting a universal manifold.

The spirit of the present sad moment is most eloquently described by the wonderful artist Vincent van Gogh in a letter he wrote to his younger brother Theo,

"I do not intend to spare myself, to avoid emotions or difficulties. I do not care whether I live for a shorter or longer time. The world concerns me only in so far as I feel a certain debt towards it. Because I have walked on this earth for thirty years and out of gratitude I want to leave some souvenirs."

In closing, I read an English translation of a short poetry I wrote (originally in Persian language) a few years ago called "Wheels of Cosmos":

The turning wheels of Cosmos beyond our control ...

For the moments already passed, return no more ...

Yesterday was sacrificed so that today we could be ...

But today about our tomorrow, alas, we cannot see...

\section{References}

1. Kistler AL (1959) Fluctuation measurements in a supersonic turbulent boundary layer. Phys Fluids 2: 290-296.

2. Dopazo C (1977) On Conditioned Averages for Intermittent Turbulent Flows. J Fluid Mech 81(3): 433-438.

3. Sohrab SH (2016) On a scale-invariant model of statistical mechanics and the laws of thermodynamics. ASME J Energy Resources and Technology 138: 1-12. 